\title{
A PROPOSED TYPOLOGY OF THE MILITARY BULLY
}

\section{Donovan Kalamdien and Audrey Lawrence Stellenbosch Universityl}

\begin{abstract}
Workplace bullying is a pervasive problem faced by organisations globally. Although progress has been made in augmenting our understanding of the phenomenon within diverse work settings, the military remains one work environment where dialogue into the phenomenon is not forthcoming. Scientific enquiry into bullying in the military is virtually non-existent. The aim of this study was to provide a conceptual analysis and review of workplace bullying literature, whilst also characterising the personas of military bullies and initiatives to assist them in correcting their behaviour. The associated costs to an organisation necessitate the urgency with which this issue needs to be addressed, especially within the military environment.
\end{abstract}

\section{Introduction}

Bullying, as a type of antisocial deviant behaviour, in which one or more people is continually being subjected to unwelcome negative and harmful acts by one or more other people, has long been synonymous with schoolchildren. It was not until the pioneering works of family therapist Heinz Leymann ${ }^{2}$ that bullying among adults in the workplace began to attract the academic and public attention it presently receives. Leymann, ${ }^{3}$ albeit using the term 'mobbing', provided the first empirical confirmation of bullying in the workplace. Whilst applauding the work of Leymann ${ }^{4}$ and recognising the subsequent acclaim, it is argued that employees' prolonged exposure to systematic forms of maltreatment at work has occurred ever since people started interacting with each other in an occupational setting. ${ }^{5}$

Scientia Militaria, South African Journal of Military Studies, Vol 45, No. 1, 2017, pp. 122-144. doi : $10.5787 / 45-1-1196$. Creative Commons License-CC BY-NC-ND 4.0
Increased curiosity into this long-existing psychosocial workplace problem is thus purely the result of the emergence of concepts such as 'bullying'. With the recognition of the concept 'bullying' merely comes an awareness of the actual 
prevalence and significance of this enduring problem. ${ }^{6}$

An appraisal of existing literature increasingly underscores the transcendent nature of workplace bullying. Maree ${ }^{7}$ concludes that bullying is not exclusively present in schools, but is present at all levels of society: in the family, in tertiary institutions, and in the workplace. Likewise, Pietersen ${ }^{8}$ refers to workplace bullying as a universal phenomenon. Research in the social sciences recurrently suggests it to be prevalent across various organisational sectors, ${ }^{9}$ while disturbing findings about the negative psychological and physiological consequences accompanying the phenomenon for the victim, organisation and onlooker are also being reported. ${ }^{10}$

In spite of the widespread attention bullying receives in diverse organisational settings, the military still remains one environment where dialogue into bullying is lacking. As recognised by Østvik and Rudmin, ${ }^{11}$ "despite the expectation and the evidence that military units, like other organizations, have problems with bullying and hazing, there have been few, if any, systematic social science studies of this reported in the mainstream research literature". To demonstrate, in South Africa for example, apart from the work by Kalamdien, ${ }^{12}$ no other scientific inquest into bullying within the South African National Defence Force exists. This lack of bullying literature stemming from military environments in mainstream literature, is reasoned to be the case for many countries and defence forces around the globe. The matter should be of great concern, considering the numerous other distinctive stressors soldiers have to contend with in the military. ${ }^{13}$ As social institutions, military institutions can also be expected to experience bullying and are therefore not immune to it, as is evident in the work of Østvik and Rudmin and Kalamdien. ${ }^{14}$ Akin to numerous workplace bullying studies, Østvik and Rudmin and Kalamdien ${ }^{15}$ in their inquiries recounted bullying prevalence rates, tactics, causes and risk groups within the military. Their work is however considered merely a validation of the prevalence of bullying in the military.

Of parallel importance, which is not facilitated in any military bullying literature presently available, is the attainment of a richer understanding of the perpetrators, ways to address the perpetrators appropriately, and to combat bullying entirely in the military. Essentially, perpetrators in the military function within a significantly different workplace climate and culture as opposed to their civilian counterparts, hence giving them a rather altered persona. Perpetrators in the military exist in a workplace with an extremely and uncompromising hierarchical structure with defined roles, ranks and career fields. They follow explicit rules of conduct and clearly defined career paths. On the other hand, perpetrators in the civilian environment function under conditions that are considered more flexible 
and less defined. For example, rules of conduct are frequently implied and career progression is less explicit. Importantly, from their inception, perpetrators in the military are being indoctrinated and socialised around violent actions reasoned acceptable and needed under certain conditions, which is not at all the case with perpetrators in the civilian environment. Various behaviours thus considered appropriate in the military are deemed inappropriate in the civilian setting. The present article will therefore specifically refer to perpetrators of bullying in the military as either 'military bullies' or 'a military bully'.

In light of the preceding discussion, the aim of this article is threefold: Firstly, to summarise and enrich literature personifying the perpetrator(s) of workplace bullying; secondly, to contextualise bullying in the military environment; and thirdly to propose actions to discourage and/or neutralise the 'military bully' and to combat the occurrences of bullying in the military. The research approach followed is theoretically descriptive and exploratory in nature. To achieve the aforementioned aims, bullying literature from South Africa and abroad will be used collaboratively.

\section{The military culture}

The Centre for Strategic and International Studies ${ }^{16}$ broadly defines military culture as:

... an amalgamation of values, customs, traditions and their philosophical underpinnings that, over time, has created a shared institutional ethos. From military culture springs a common framework for those in uniform and common expectations regarding standards of behaviour, discipline, teamwork, loyalty, selfless duty, and the customs that support those elements.

According to Heinecken, ${ }^{17}$ "military culture is the genetic code that defines military service and the conduct of those in uniform". This is advanced through the socialisation or enculturation of civilian men and women into a very specific military culture, which is a process of indoctrinating them with the values, ideas and customs of the military. ${ }^{18}$ The process of indoctrination plays out in an environment that Archer $^{19}$ considers to typify a strong culture in that it characterised by the following: rank structure, power base, highly prescriptive and unique punitive code and practices, promoting uniformed members from within, long-standing traditions, predominantly male-dominated, authoritarian and hierarchical, team- and/or group-focused, and basic recruitment training. It is essential to note that, as much as these characteristics are indispensable to military 
cohesion and effectiveness, they can also create a climate conducive to bullying in the military, and serve as an enabler to the 'military bully'.

\section{The concept of bullying in the military}

In their study involving Norwegian Army soldiers, Østvik and Rudmin 20 define bullying as involving "a physically or socially more powerful person, or group of people, intentionally harassing or hurting a weaker person by physical, verbal, social or psychological means". Presenting a more elaborate definition, Kalamdien $^{21}$ in his dealing with South African soldiers defines bullying as follows:

Workplace bullying refer[s] to situations where one or more persons are subjected to persistent and repetitive harmful negative or hostile acts (excluding once-off isolated incidents) by one or more other persons within the workplace (excluding incidents where two equally strong individuals come into conflict). The person should feel helpless and defenceless in the situation. The victim should experience the harmful negative and hostile acts repetitively and persistently for at least six months as offensive. The intention of the perpetrator is considered insignificant.

It should be noted that the more stringent definition applied by Kalamdien $^{22}$ is parallel to most workplace bullying definitions used by leading authors writing and reporting on the phenomenon, ${ }^{23}$ in that it highlights four essential elements in qualifying an act as bullying:

Firstly, the target person is systematically being subjected or exposed to unwanted harmful acts. These acts consist of either direct or indirect person- or work-related deeds. ${ }^{24}$ Person-related behaviour includes direct bullying such as yelling, verbal attacks, belittling remarks, personal jokes, threats, intimidation and manipulation, whilst indirect bullying could involve ignoring, excluding, isolation, gossip, lies, undermining and false accusations of the targeted person. Workrelated behaviour takes the form of work overload, removing responsibility, unrealistic goals, setting up to fail, overruling decisions, controlling resources, withholding information, excessive monitoring, judging work incorrectly, unfair criticism, blocking promotion and delegation of menial tasks. ${ }^{25}$

Secondly, the acts are repeated regularly and persistently. This implies that the target person is not subjected or exposed to a once-off isolated incident but rather to a number of incidents on a regular and persistent basis. It is common for the perpetrator to subject the target person to a blend of overt and covert harmful deeds rather than one single act. By definition, isolated incidents therefore would not be considered bullying. 
Thirdly, the target person should experience the harmful acts for a period of time, hence the continual occurrence of the acts. Scholars like Matthiesen and Einarsen ${ }^{26}$ prefer the target person to experience bullying behaviour for at least six months before such person can be regarded as a victim of workplace bullying. This provides a reasonable period for safely concluding whether or not a person is being bullied, or whether or not a person can be regarded as a 'military bully'. In this article, it is argued that the period of at least six months becomes immaterial in the case where the bullying tactics are applied with an increased frequency, for example daily, or for a shorter period, for example two or three months. In such cases, the increasing frequency with which the acts occur becomes more relevant than the timeline in qualifying a person as either the victim or a military bully.

Lastly, there is either a real or perceived power disparity between the perpetrator and target person, hence the target person's failure to put up a fight. This power imbalance renders the target person defenceless and helpless in the situation. Importantly, the power imbalance does not exclusively originate from formal positions or levels of responsibility but could also be socially constructed. As Owoyemi ${ }^{27}$ recognises, the power imbalance between the perpetrator and his or her victim in the workplace can be established through formal position, authority, control over resources, intelligence, level of education, experience, coalition, gender, physical size, and so forth.

In the light of the preceding discussion, the following definition of bullying $^{28}$ in the military is being advocated:

Bullying in the military refer[s] to instances where one or more persons, regardless of their social or organisational status, are subjected to recurring negative and hostile behaviours perpetrated by one or more others, irrespective of their social or organisational status and intention, over a period of time (six months unless the bullying tactics is applied with an increased frequency, in which case a shorter period will apply based on the frequency of the bullying). It is immaterial whether or not the person(s) exposed to the negative treatment is capable, find it trying or inept in defending the self, or whether or not they experience any psychological, physiological or social health complaints as a result of the exposure. What are essential are the actions of the military bully and the prospect that his or her actions may cause psychological, physiological or social health complaints in any other person.

The suggested definition notably takes into account all four elements routinely found in most workplace bullying definitions as previously discussed. However, the proposed definition goes further by suggesting that the timeframe 
frequently applied by leading scholars like Einarsen et al. and Vie et al. ${ }^{29}$ should in some instances be used as a guideline rather than the norm, while also acknowledging that people differ with reference to their level of resilience and coping ability. In the case of the latter, greater emphasis is subsequently being placed on the act itself rather than on its effect on the targeted person.

In the light of the preceding discussion, bullying is regarded as a psychosocial workplace problem distinct from harassment for several reasons. First, the conduct of the military bully is not necessarily illegal and would often not constitute harassment. According to Smit, ${ }^{30}$ the top bullying acts or omissions (blame for errors, unreasonable job demands, criticism of ability, inconsistent compliance with rules, threat to job loss, insults and put-downs, discounting, denial of accomplishments, exclusion or 'ice-outs', yelling, screaming, or stealing another's credit) are not illegal. Second, harassment requires a clear bias towards the victim based on a protected ground (e.g. sex, race, gender, disability or sexual orientation), which is not the case with workplace bullying. Lastly, a single incident or action on the part of an individual can be assessed and qualified as harassment; more than one incident or action is required for workplace bullying to exist. $^{31}$

\section{The prevalence of workplace bullying}

Workplace bullying is well documented as one of the fastest-growing workplace problems threatening overall organisational well-being. Frequency studies commonly signify that an alarming number of employees are subjected and exposed to continual maltreatment in the workplace. The majority of research on workplace bullying has notably been conducted within either the health ${ }^{32}$ or educational $^{33}$ sectors. There are disturbing statistics reported from other industries.

To illustrate, Østvik and Rudmin ${ }^{34}$ assessed the prevalence of bullying among Norwegian Army soldiers. In his study with South African soldiers, Kalamdien $^{35}$ reported a prevalence rate as high as $60 \%$. Similarly, Berry, Gillespie, Gates and Schafer's study ${ }^{36}$ of novice nurses with 197 respondents found that $72.6 \%$ of the nurses reported experiencing a workplace bullying event during the previous month. However, when they applied a stricter criterion of being bullied daily over a 6 -month period, they found that $21.3 \%$ self-identified as being targets of workplace bullying. Research in the South African health sector conducted by Steinmann and Du Toit $^{37}$ showed prevalence rates ranging between $61.8 \%$ and $77.8 \%$. In certain studies, extremely high rates of $90.8 \%{ }^{38}$ are being reported. Lastly, Bentley et al. ${ }^{39}$ in their study of 332 respondents from the New Zealand retail and business travel industry found that $11.4 \%$ of respondents in their sample 
self-identified as being victims of bullying, based on the criterion that self-reported victims had to have experienced at least two negative acts weekly for a period of six months. It is imperative to take cognisance of the fact that the differences in reported prevalence rates are influenced by the particular frequency criterion being applied, one's conceptualisation of the phenomenon, and the sample size of respondents.

Frequency studies habitually also underline the status and gender of the victim and perpetrator. Hoel, Cooper and Faragher ${ }^{40}$ in their study found that $74.7 \%$ of victims reported that they had been bullied by a superior. Similarly, Berry et al. ${ }^{41}$ found that the main reported perpetrators of workplace bullying (44\%) were nurses in leadership positions. Although superiors are frequently documented as the most common perpetrators of workplace bullying, the perpetrator could also be a peer or subordinate. ${ }^{42}$ For example, Hoel et al. ${ }^{43}$ found that $36.7 \%$ of victims reported a peer as the perpetrator, whilst $6.7 \%$ reported to have been bullied by a subordinate. Likewise, Glaso, Bele, Nielsen and Einarsen ${ }^{44}$ found that $61.2 \%$ of respondents reported to have been bullied by peers. Ortega, Christensen, Hogh, Rugulies and Borg ${ }^{45}$ found that $72.4 \%$ of victims identified a peer as the perpetrator and $16.2 \%$, a superior. In essence, workplace bullying is thus not exclusively unidirectional in the sense that the perpetrator is not always a superior.

In the case of being a victim of workplace bullying, minor differences between males and females are commonly reported. Ortega et al. ${ }^{46}$ found in their study that $13.7 \%$ of males reported having been bullied, as opposed to $11.8 \%$ of females. Similarly, Keuskamp, Ziersch, Baum and LaMontagne ${ }^{47}$ in their crosssectional study found that $16.5 \%$ of males reported having been bullied, as opposed to $14.1 \%$ of females. It therefore seems that both males and females are equally vulnerable to become victims of workplace bullying. The same can be said about the perpetrator in that both males and females actively participate in workplace bullying despite some reported differences. In the study by Kalamdien, ${ }^{48}$ both men and women were reported as being military bullies. Evidence further suggests that men are more likely to be bullied primarily by other men, whilst women are more likely to be bullied mainly by other women. Hoel et al. ${ }^{49}$ in their cross-sectional study found that $62.2 \%$ of men reported having been primarily bullied by other men as opposed to $37.3 \%$ of women who reported being bullied mainly by other women. It is also likely for men to be exclusively bullied by women, and women to be exclusively bullied by men. Any person employed in the military could thus potentially become either a military bully or victim, irrespective of their real or perceived status among the ranks. 


\section{The effects of workplace bullying}

Several large-scale studies have shown that workplace bullying has numerous negative consequences for the victim, observer and the organisation. Evident in most studies is that the phenomenon detrimentally affects the victim's overall health and well-being. Victims of workplace bullying have been found to suffer from physiological (e.g. headaches, increased blood pressure, migraine, sleep disturbances, nausea and skin rashes), psychosomatic and psychological problems (e.g. fear, anxiety, panic attacks, low self-esteem, depression, anger, social maladjustment, social isolation, chronic fatigue, compulsions and despair). ${ }^{50}$ Vie, Glaso and Einarsen ${ }^{51}$ found in their study of 1024 employees in a Norwegian bus company that the victims of workplace bullying in their sample reported being more afraid, angry, upset, guilty, nervous, hostile, scared, stressed, ashamed and frustrated as opposed to the non-victims. Additionally, workplace bullying has also been documented to be strongly related to symptoms indicating the experience of post-traumatic stress. ${ }^{52}$ Moreover, the negative effects of workplace bullying also spill over into the victim's personal life, thus negatively affecting the victim's relationships with family and friends. In a nutshell, workplace bullying is an extreme social stressor that affects all facets of the victim's life.

The effects of workplace bullying are not restricted solely to the victim. Although not physically on the receiving end of workplace bullying, those who are simply spectators of the phenomenon in the workplace also suffer from the negative effects associated with it. Akin to victims, onlookers also experience increased levels of strain and decreased levels of productivity. ${ }^{53}$ Sims and Sun ${ }^{54}$ studied the effects of workplace bullying on witnesses with a sample of 150 employees in the Chinese manufacturing industry. Their findings indicated that witnesses of workplace bullying are more likely to report an increase in symptoms of strain. Additionally, employees who witness workplace bullying were also found to report decreased job satisfaction and diminished employee commitment. Likewise Bentley et al. ${ }^{55}$ found in their study of 332 employees in the New Zealand travel industry that those witnessing workplace bullying reported higher levels of stress, poor emotional well-being, lower levels of performance, lower effective commitment to the organisation, a greater intention to leave, and a more negative perceived experience of work.

Parallel to the negative effects that workplace bullying has on the victim and witness is the substantial negative consequences it has for the organisation in which it thrives. The negative effects of workplace bullying also stretch well beyond the physiological, psychosomatic and psychological state of the victim and witness. Workplace bullying has been well documented to influence a person's 
work and attitude to work negatively. ${ }^{56}$ Those responsible for organisational success cannot afford to ignore the phenomenon. Berry et al. ${ }^{57}$ found in their study in the healthcare environment that $46.7 \%$ of their respondents reported decreased productivity. In the study of people with school-level education, Jacobs and De $\mathrm{Wet}^{58}$ found that $35 \%$ of respondents reported doing things unrelated to their work, they were unable to get work done during their free time, and were feeling detached from their work. Severe workplace bullying ultimately creates an increased desire to leave the organisation. ${ }^{59}$ Moreover, victims of workplace bullying are reported to become stressed, they experience a very low level of morale and reduced job satisfaction, they are more likely to be absent from work, have lower organisational commitment and work motivation, contemplate leaving the organisation on a regular basis, and they report sick more than usual. ${ }^{60}$ It would be safe to conclude that these factors play a profound role in the overall well-being and success of any organisation.

Whilst victims of workplace bullying are the recipients of the negative effects, the organisation is directly compelled to bear the associated costs. Organisational costs include recurring staff turnover and recruitment costs, increased workers compensation claims, early retirement costs, litigation costs, decline in productivity, organisational ineffectiveness, salary payments for employees on continual sick leave, and a loss in organisational income. ${ }^{61}$ At the extreme, bullying in the military could also result in suicidal ideation and acting out, as well as the killing of others. ${ }^{62}$

\section{The military bully}

Notwithstanding individual military status and arrangement, every person has the potential to become a military bully. That is not to say that everyone will definitely be one at some point during his or her service in the military.

Literature on workplace bullying ordinarily contains some reference to the perpetrator. However, only a few researchers have actually gone as far as to classify or personify the bully. Social psychologists, Gary and Ruth Namie were the first to classify bullies based on the various tactics employed. ${ }^{63}$ This was followed by Keryl Egan whose classification of bullies was grounded in the reasons of why people bully, ${ }^{64}$ which much resembles earlier work done by Einarsen. ${ }^{65}$ A succinct synopsis of the aforementioned authors' classification of bullies is provided in Table 1. It is imperative not to dispose of the probability that any one of the mentioned personas in Table 1 may very well embrace the characteristics normally associated with another. 
Namie $^{66}$ mentions that classifying bullies as narcissists and/or as antisocial would be convenient. It will then require efforts to be focused just about entirely on rehabilitating individuals. However, the American Psychiatric Association (as cited in Namie) ${ }^{67}$ found that only about $4 \%$ of bullies sincerely have a personality disorder. This implies that a small percentage of military bullies could then debatably be expected to have a personality disorder, while the majority exist for reasons other than a personality disorder.

In light of the foregoing discussion, the study reported here classifies military bullies into six categories, namely 1) 'historian', 2) 'opportunist', 3) 'retaliator', 4) 'compensator', 5) 'defenceless duck', and 6), 'infant'. These personas will at times either twin with or resemble the personas and characteristics presented in Table 1. It should therefore become clear that military bullies should not be thought of as either or. In addition, we will also highlight that each of the advocated classifications of military bullies could embrace any of the traits characterising each of the personas acknowledged in Table 1.

The 'historian' symbolises a military bully who has a history with bullying in other contexts, the genesis of which could very well be traced back to his or her school and childhood days. In some cases, the historian merely transferred his or her bullying tendencies from the schoolyard and childhood days to the workplace and adult life, whilst in other instances, the bullying behaviour shown by the historian may be an imitation of those he or she had been subjected to as a child. ${ }^{68}$ The origin of such dysfunctional tendencies might also exist during a defined epoch in the historian's vocational or military life. In both instances the historian has cultivated a disposition towards the bullying of others. The reasons for this could be varied or might constitute any one or more of those emphasised in Table 1.

In an environment where the military bully functions without any kind of confrontation or collecting any form of support and encouragement for his or her damaging behaviour, he or she is likely to continue, ${ }^{69}$ thereby prolonging his or her reign. Given the nature of the military, it is reasoned that many instances do exist where the counterproductive behaviour of some military personnel goes unaddressed. Bullying can be one in many behaviours that go unchecked in defence forces. Over time, the historian might have become nonchalant and reckless in his or her demeanour, making him or her more readily recognisable. Inversely, he or she may employ learned skills and tact to camouflage his or her behaviour to such a degree that it is literally impossible to identify and classify it as bullying. ${ }^{70}$ This is especially challenging where the military bully uses military structures, processes, policies and practices to bully others. 
Table 1: Persona and characteristics of bullies. (Table compiled by the authors from data by Einarsen, Egan and Namie) $)^{71}$

\begin{tabular}{|c|c|c|c|c|c|}
\hline \multicolumn{2}{|c|}{ Namie, 2003} & \multicolumn{2}{|c|}{ Egan, 2005} & \multicolumn{2}{|c|}{ Einarsen, 1999} \\
\hline Persona & Characteristics & Persona & Characteristics & Persona & Characteristics \\
\hline Screaming Mimi & $\begin{array}{l}\text { Emotionally unstable } \\
\text { No desire to be discrete } \\
\text { Use behaviour to instil } \\
\text { fear in others }\end{array}$ & \multirow[t]{2}{*}{ Accidental bully } & \multirow{2}{*}{$\begin{array}{l}\text { Personally blunt about } \\
\text { personal actions } \\
\text { Lacks intention } \\
\text { Aggressive and } \\
\text { demanding } \\
\text { Commonly respond out of } \\
\text { panic or stress }\end{array}$} & \multirow{4}{*}{ Predatory } & \multirow{4}{*}{$\begin{array}{c}\text { Consider as easy } \\
\text { targets } \\
\text { Act without } \\
\text { provocation }\end{array}$} \\
\hline \multirow[t]{2}{*}{ Constant critic } & \multirow{2}{*}{$\begin{array}{l}\text { Hypercritical of others } \\
\text { Disguises own } \\
\text { shortcomings } \\
\text { Willing to engineer } \\
\text { inadequacies in others }\end{array}$} & & & & \\
\hline & & \multirow{3}{*}{$\begin{array}{l}\text { Destructive self- } \\
\text { absorbed bully } \\
\text { (narcissistic) }\end{array}$} & \multirow{3}{*}{$\begin{array}{c}\text { Fragile self-esteem } \\
\text { Inflated and unrealistic } \\
\text { view of self } \\
\text { False sense of entitlement } \\
\text { Devalue and critical of } \\
\text { others } \\
\text { Craves power } \\
\text { Vulnerable to humiliation }\end{array}$} & & \\
\hline \multirow{3}{*}{$\begin{array}{l}\text { Two-headed } \\
\text { snake }\end{array}$} & \multirow{3}{*}{$\begin{array}{l}\text { Slithers around through } \\
\text { fierce deeds upon others } \\
\text { Defraud and defame } \\
\text { others to boost self-image } \\
\text { Spread malicious rumours } \\
\text { about others } \\
\text { Value only the self }\end{array}$} & & & & \\
\hline & & & & \multirow{3}{*}{$\begin{array}{l}\text { Dispute- } \\
\text { related }\end{array}$} & \multirow{3}{*}{$\begin{array}{l}\text { Conflict or } \\
\text { disagreement } \\
\text { with victim }\end{array}$} \\
\hline & & & \multirow[b]{2}{*}{$\begin{array}{l}\text { Intentionally harms } \\
\text { others, Deceitful } \\
\text { Appears charming and } \\
\text { grandiose } \\
\text { Frighten others into } \\
\text { compliance, Seductive, } \\
\text { Lack remorse } \\
\text { Very systematic }\end{array}$} & & \\
\hline Gatekeeper & $\begin{array}{l}\text { Obsessively control } \\
\text { resources; Allocate } \\
\text { resources to the } \\
\text { detriment of others } \\
\text { Identify, highlight and } \\
\text { complain about others } \\
\text { failures }\end{array}$ & $\begin{array}{l}\text { Psychopathic } \\
\text { bully }\end{array}$ & & & \\
\hline
\end{tabular}


The most viable response to the historian's actions is to encourage him or her to correct his or her behaviour. It should however be noted that it might be testing for the historian to unlearn the behaviour that has defined him or her for several years, especially when the military bully does not consider his or her actions as wrong. The historian could however be assisted in correcting his or her behaviour through coaching. Lussier" ${ }^{72}$ defines coaching as "the process of giving motivational feedback to maintain and improve performance", which involves describing current performance and desired performance, securing a commitment to change, and following up. In the case of the military bully, this would imply describing to him or her the destructive and damaging nature of his or her current behaviour, clearly defining what would be considered not only appropriate but also desired behaviour, communicating the importance of adjusting his or her behaviour and securing his or her commitment to change, and to follow up in order to ascertain whether he or she has indeed changed his or her behaviour. It is imperative that constant encouragement and feedback be provided to the military bully throughout the process.

The 'opportunist' signifies a military bully who habitually desists bullying unless an environment, situation or personality encourages, permits or shields such bullying, or when the bullying is applied as a means of satisfying personal interest. In the case of the former, the military bully is vigilant of enabling factors in the environment. ${ }^{73}$ For example, the opportunist may only bully others when in command and control of them. Likewise, he or she may only bully people when his or her actions are incorrectly perceived, accepted, allowed and encouraged by individuals in the military leader group as exercising effective command and control, and subsequently rewarded. ${ }^{74}$ All the while, in reality, it is bullying and has a widespread damaging effect. Furthermore, the military bully's perceived relationship with senior military personnel and the expected protection that such relationship affords may provide the needed impetus to bully, while also discouraging any type of response. A person who desires to progress up the military chain of command may well resort to bullying if it either heightens or ensures his or her progression through the ranks. Motsei ${ }^{75}$ reports that hierarchical and bureaucratic organisations, which often nurture dictatorial leadership (of which the military is considered a near textbook example), often serves as a precursor of bullying.

Given the opportunist's lack of self-confidence and opportunistic nature, he or she can still be coached out of his bullying tendencies. Effort should be made to limit, or ideally eliminate, the opportunities this military bully has utilised. In essence, to stop the opportunist requires the removal of the enabling forces in the military. Confronting and informing the opportunist of his unacceptable conduct 
could prove invaluable in ending his or her behaviour and preventing him or her from continuing.

The 'retaliator' represents a military bully who intentionally bullies another person as a means of responding to a real or perceived wrong the targeted person has done to him or her or someone with whom he or she has a close relationship. It may well be that the military bully feels offended because he or she is of the understanding that the target person has put him or her in an unfavourable or embarrassing position amongst the ranks, irrespective of whether it was intended or not, and that this is unacceptable. Although conflict may in some instances constitute an antecedent of bullying, in this regard, it does not necessarily imply that it always will. There may be several instances where the military bully is in conflict with someone or others without feeling the need to bully them. Unless the retaliator feels offended or threatened by the conduct of others he or she is unlikely to bully them. Often this person has an unforgiving personality and cannot easily let go of things. Retaliators will stop once they are personally satisfied that the victim has suffered enough, or satisfied that the victim has done enough to redeem him- or herself. In some instances, retaliators just have a need to bully without any real provocation. This can include instances where the victim is perceived as a threat to the retaliator's advancement or status in the military. In such a case, the retaliator may opt to spread malicious rumours about the target, feed the target wrong information, or withhold essential information from the target.

The retaliator demands a more focused approach in the form of psychotherapy. According to Waldinger, ${ }^{76}$ psychotherapy aims to provide an individual with new experiences which are designed to enhance the individual's capacity to handle subjective distress and to engage in meaningful relationships and satisfying work. The purpose would be to expose the retaliator to a therapeutic process where sense can be made of his or her need to retaliate and consider better ways of responding to personally undesirable events at work. Since the retaliator perceives certain environmental stimuli as disturbing it would also be helpful to encourage him or her to participate in behaviour treatments based on learning approaches, such as systematic desensitisation. Through systematic desensitisation, the retaliator will learn how to handle disturbing stimuli while remaining emotionally calm. ${ }^{77}$

The 'compensator' characterises a military bully who resorts to bullying as a means of compensating for some or other personal, social or professional inadequacy. ${ }^{78}$ Moreover, the compensator accepts bullying as a means of exercising control in areas of his or her life due to the lack thereof in other areas. As such, this form of military bully believes that by exerting greater control in one 
area of his or her life, where he or she can legitimately and without restriction exercise such control, he or she will regain the control he or she has lost in another. This might be a military bully who has limited to no control over matters at home and aims to gain greater control over conditions at work where his or her position, authority or status in the military offer him or her the opportunity. The same can be said of the military bully who has no influence on his or her peers or superiors and decides to exert greater influence over his or her subordinates. This could signify a strong ego-defence mechanism of the compensator in the form of displacement, by redirecting his or her emotions and actions from the real source to a substitute (the victim). ${ }^{79}$

Generally, the compensator will cease his or her bullying once his or her inadequacies or lack of control have been satisfied. It is argued that there would thus be no need or reason to pursue something that is not lacking or lost, at least not to the degree of bullying someone. Within the scope of the military, efforts should be made to identify and cater for the compensator's inadequacies. Akin to the retaliator, the compensator may also require an initiative such as psychotherapy. This could be especially therapeutic in instances where the military bully is unaware of his or her inadequacies or where he or she lacks the necessary insight to deal with it effectively.

The 'defenceless duck' denotes a military bully who is considered to be not entirely in control of his actions. In this instance, the military bully exists as a result of some form of psychiatric disorder that could feature impulsivity ${ }^{80}$ among others (e.g. conduct disorder, borderline personality disorder, mood disorder or narcissistic personality disorder), and not necessarily for the reasons that other bullies exert these behaviours. To some point, this military bully becomes an involuntary perpetrator of workplace bullying. However, regardless of the involuntary nature of the behaviour(s) the effects remain real, and as such are and should still be considered unacceptable.

Considering the fact that the defenceless duck is affected by what could be considered to be abnormal behaviour, in that the behaviour can be considered unusual, excessive, inappropriate or violating social norms in situations, ${ }^{81}$ assistance from a healthcare professional (e.g. psychologist, therapist or psychiatrist) would be necessary to manage the particular disorder. ${ }^{82}$

The 'infant', unlike any of the already cited bullies who might have bullied others for a number of years, indicates a military bully who is at the dawn of his or her potentially bullying footprint. It may well be that the infant has witnessed other military bullies in action and decided to emulate their injurious behaviour. The 
infant could potentially launch, and eventually continue, his or her bullying under the guardianship of a superior who acts as an enabler.

Likewise, the superior may encourage the infant to bully others under the mistaken notion that it is 'making the infant tough', is a form of 'tough management', or that the targeted person deserves the treatment. The infant may have been wrongly taught or he or she may consider the type of bullying tactics used to be acceptable in the military, while in reality it is not.

The infant can still be coached out of bullying. Generally, confronting the infant during the inaugural phase of his or her likely bullying history will result in him or her refraining from any future bullying. It is important to reemphasise to the infant which type of behaviours is considered desirable, acceptable and beneficial to the military and its personnel. The infant's exposure to a moral induction programme and socialisation climate is therefore essential.

In certain instances military bullies could present themselves as hybrids due to them having multiple identities, in that they manifest more than one of the six personas. Furthermore, the duration of the bullying behaviours by these personas can be persistent or nascent, or a combination of both. Table 2 provides a succinct overview of the duration of the bullying behaviour associated with each of the six personas.

Of further relevance is the extent to which the bullying behaviour is triggered by environmental factors. The historian (because of learned behaviour) and the defenceless duck (because of pathology) will behave consistently regardless of context. In many cases, the conduct of the infant, opportunist, retaliator and compensator will be a reaction to situational factors. An understanding of the six advocated personas of military bullies could facilitate an appropriate response.

Table 2 Duration of bullying behaviour

\begin{tabular}{|c|c|c|}
\hline \multicolumn{3}{|c|}{ DURATION OF BULLYING BEHAVIOUR } \\
\hline Nascent & Intermittent & Persistent \\
\hline Infant & $\begin{array}{c}\text { Opportunist } \\
\text { Retaliator } \\
\text { Compensator } \\
\text { Defenceless Duck }\end{array}$ & Historian \\
\hline
\end{tabular}




\section{Why address bullying in the military?}

As a social institution, the military is as vulnerable as any other establishment to episodes of bullying. The occurrence of bullying in the military should be an area of enormous concern for several reasons. First, the military is of necessity a hierarchical body. As a result, the organisation is characterised by a dominant leader-follower hierarchy and chain of command structure, which could serve as the breeding ground for bullying. ${ }^{83}$ Those in leadership positions can abuse their organisational status and employ the organisational chain of command as a vehicle for bullying others in the military.

Second, central to the development of military personnel (from organisational entry through to organisational exit) is their indoctrination and inculcation to a range of essential military values (e.g. respect, integrity, loyalty, duty, courage, etc.) and the premise of discipline as well as mental and physical toughness. Notwithstanding the importance and usefulness of these elements to the military, they could provide opportunities for bullying to occur amongst the ranks. These elements could foster a psychosocial work environment where bullying behaviours could be considered customary. Victims of bullying in the military could wrongfully underplay their experiences as they - and others - expect and demand of themselves to be tough enough to soldier through their experiences.

Furthermore, uniformed members are being trained and conditioned for combat. By design they could become extremely aggressive and hostile in conditions where they feel threatened or fenced in, which could become devastating. This should be alarming considering that they often have access to weapons and ammunition. The experience of bullying in the military could present one such instance when military personnel could feel threatened and fenced in, and in the process, become aggressive and hostile as they attempt to escape the situation. Østvik and Rudmin ${ }^{84}$ highlight that military personnel, especially uniformed members, are often isolated from moderating social norms and institutions, and they are frequently incapable of leaving the military if they feel abused. These conditions, and the member's experience of bullying, could result in suicide or the death of the victim, perpetrator or even innocent bystanders.

Bullying in the military undermines the fundamental rights (e.g. human dignity) of victims as they are subjected to inhuman and immoral treatment. It also signifies perpetrators' extreme disregard for the values and norms of the military. This could potentially cast doubt in the hearts and minds of victims and bystanders over their own belief in military values and norms. Furthermore, bullying threatens the valued trust and respect amid military personnel, as well as the trust and respect 
members have in the organisation. ${ }^{85}$ Trust and respect could be replaced by feelings of bitterness, anger and frustration towards others and the military itself.

Workplace bullying affects an entire organisation. The military is not immune to this. The prevalence and extent of bullying in the military could contribute to an unhealthy defence force. This directly threatens the operational effectiveness of the organisation. An unhealthy military force translates into an ineffective military force. The experience of bullying by military personnel could negatively affect their work and particularly their attitude to work. ${ }^{86}$ This also implies an unhealthy military community as military families also present secondary victims of workplace bullying.

Unchecked bullying has the potential to tarnish the image of the military. Those employed in the military could perceive their work environment as toxic. This could result in high turnover rates and the loss of valuable skills and experience. Those seeking employment would become reluctant to join the military, as they might perceive the organisation to be toxic and personally harmful. This could be especially troublesome as the military increasingly seek to attract professional and expert individuals. Maintaining a positive image should therefore be of cardinal importance to any military.

\section{Recommendations for future research}

As this was an exploratory study, a purely conceptual analysis and review of workplace bullying literature was provided. This provides a necessary first step in addressing bullying in the military. In order to gain a deeper understanding of bullying in the military, continued dialogue into the phenomenon within the military is needed with a more systematic research approach. The use of wellconceptualised research strategies (qualitative and quantitative) aimed at discovering the extent of the phenomenon, and steps aimed at minimising the effects thereof are needed. This would provide valuable information (and data to be used for analysis) on the nature and prevalence of bullying in the military. Second, investigation into workplace bullying in the military should attempt to ascertain the effects and costs thereof for the victim, perpetrator, bystander and the organisation. Moreover, scientific enquiry should also aid the military in responding to and addressing incidents of workplace bullying.

\section{Conclusion}

Workplace bullying is a pervasive problem threatening all workplaces, and is too costly to ignore. This is emphasised by the ever-expanding body of literature 
that highlights its prevalence and effects on the total organisation. Ignoring the severity of workplace bullying and disregarding the attention it deserve only places the military at an increased risk of falling prey to its negative effects, which will threaten its operational effectiveness. It therefore requires the military to acknowledge that it is not immune to workplace bullying and the associated costs. Such acknowledgement would facilitate the need for obtaining a better understanding of the phenomenon, as well as encourage directed efforts to address and combat it speedily.

\section{Endnotes}

${ }^{1}$ Donovan Kalamdien conducted this research as part of a Masters' degree while at the SA Military Academy, Stellenbosch University, and is presently an Industrial Psychologist in the SA Military Health Services. Audrey Lawrence is at the Centre for Military Studies, Stellenbosch University.

${ }^{2} \mathrm{H}$ Leymann. Vuxenmobbning-om psykiskt vald I arbetslivet [Mobbingpsychological violence at work places] (Authors' translation). Lund: Studentlitteratur, 1986.

${ }^{3}$ Ibid.

${ }^{4}$ Ibid.

${ }^{5}$ DJ Kalamdien. The nature and prevalence of workplace bullying: A comparative study. Saarbrücken: Lambert Academic, 2015.

6 J Kitt. "Workplace bullying: An overview". The Mandate Trade Union News. 12 May 2004. 6-13.

${ }^{7} \mathrm{~K}$ Maree. "Bending the neck to the yoke or getting up on one's hind legs: Getting to grips with bullying". Acta Criminologica 18/2. 2005. 15-33.

${ }^{8} \mathrm{C}$ Pietersen. "Interpersonal bullying behaviours in the workplace". SA Journal of Industrial Psychology 33/1. 2007. 59-66.

${ }^{9}$ L Cunniff \& K Mostert. "Prevalence of workplace bullying of South African employees”. SA Journal of Human Resource Management 10/1. 2012. 450465; C de Wet \& L Jacobs. "South African teachers' exposure to workplace bullying". The Journal for Transdisciplinary Research in Southern Africa 9/3. 2013. 446-464; H Miller \& C Rayner. "The form and function of 'bullying' behaviours in a strong occupational culture: Bullying in a U.K. police service". Group \& Organizational Management 37/3. 2012. 347-375; Pietersen op. cit.; RL Sims \& P Sun. "Witnessing workplace bullying and the Chinese manufacturing employee". Journal of Managerial Psychology 27/1. 2012. 9-26; D Zapf, S Einarsen, H Hoel \& M Vartia. "Empirical findings on bullying in the workplace". In S Einarsen, H Hoel, D Zapf \& CL 
Cooper (eds), Bullying and emotional abuse in the workplace: International perspectives in research and practice, London: Taylor \& Francis, 2003, $103-126$.

${ }^{10}$ S Einarsen \& EG Mikkelsen. "Individual effects of exposure to bullying at work". In Einarsen et al. op. cit., pp. 127-144; L Jacobs \& C de Wet. "A quantitative exploration of the effects of workplace bullying on South African educator". African Safety Promotion Journal 13/2. 2015. 31-58; G Namie. "Workplace bullying: Escalating incivility". Ivey Business Journal: Improving the Practice of Management November/December 2003. 1-6; OA Owoyemi. "Exploring workplace bullying in a para-military organisation (PMO) in the UK: A qualitative study". International Business Research 4/2. 2011. 116-124; TL Vie, L Glaso \& S Einarsen. "Health outcomes and self-labelling as a victim of workplace bullying". Journal of Psychosomatic Research 17. 2011. 37-43.

${ }^{11} \mathrm{~K}$ Østvik \& F Rudmin. "Bullying and hazing among Norwegian army soldiers: Two studies of prevalence - context and cognition”. Military Psychology 13/1. 2001. 19.

${ }^{12}$ DJ Kalamdien. "The nature and prevalence of workplace bullying in the Western Cape: A South African study”. MA thesis. Stellenbosch University, 2013.

${ }^{13}$ DJ Kalamdien. 2008. "A psychological support programme for peacekeeping soldiers and their families: A model for discussion”. In GAJ van Dyk (ed.), Strategic challenges for African armed forces for the next decade, Stellenbosch: SUN Press, 83-101; T Neethling. "The South African military and peacekeeping: Reflections on conditions - capacity-building and prospects". Scientia Militaria 31/1. 2003. 95-110; G van Dyk. "The role of military psychology in peacekeeping operations: The South African National Defence Force as an example". Scientia Militaria 37/1. 2009. 113-135.

${ }^{14}$ Østvik \& Rudmin op. cit.; Kalamdien, "The nature and prevalence ..." op. cit. 15 Ibid.

${ }^{16}$ Cited in A Esterhuyse. "Institutional culture: The South African military and its search for organisational stability”. In F Vreÿ, A Esterhuyse \& T Mandrup (eds), On military culture: Theory, practice and African armed forces, Claremont: UCT Press, 2013, 234.

${ }^{17}$ L Heinecken. "South African officer's views on aspects of military culture: Grappling with change and realising what needs to be done". In Vreÿ et al. op. cit., p. 249.

${ }^{18}$ Esterhuyse op. cit.; AJD Gavriel. "Red, white, or pink SA? Understanding the need for a holistic approach to culture in military intelligence". The Canadian Army Journal 13/1. 2010. 71-83. 
${ }^{19}$ D Archer. "Exploring 'bullying' culture in the para-military organisation". International Journal of Manpower 20/1\&2. 1999. 94-105.

${ }^{20}$ Østvik \& Rudmin op. cit., pp. 17-18.

${ }^{21}$ Kalamdien, "The nature and prevalence ..." op. cit., pp. 20-21.

22 Ibid.

${ }^{23}$ S Einarsen, H Hoel, D Zapf \& CL Cooper. "The concept of bullying at work: The European tradition". In Einarsen et al. op. cit., pp. 3-30; Jacobs \& De Wet op. cit.; Miller \& Rayner op. cit.; Owoyemi op. cit.; Vie et al. op. cit.; Zapf et al. op. cit.

${ }^{24}$ Cunniff \& Mostert op. cit.; C de Wet. "Educator's understanding of workplace bullying”. South African Journal of Education 34. 1. 2014. 767-783; J du Toit. "The scope of bullying among nurses in a public hospital in the Free State: A mixed-method study”. MA thesis. Stellenbosch University, 2013; M Hutchinson, M Vickers, D Jackson \& L Wilkes. "Integrating individual, work group, and organizational level factors: Testing a multidimensional model of bullying in the nursing workplace". Journal of Nursing Management 18. 2010. 173-181; NDL Motsei. "Perceptions of bullying and organisational antecedents in the South African workplace". $\mathrm{PhD}$ dissertation, University of Pretoria, 2015; Pietersen op. cit.; D Zapf \& S Einarsen. "Mobbing at work: Escalated conflicts in organizations". In S Fox \& PE Spector (eds), Counterproductive work behavior: Investigations of actors and targets, Washington, DC: American Psychological Association, 2005, 237-270.

25 JE Bartlett \& ME Bartlett. "Workplace bullying: An integrative literature review". Advances in Developing Human Resources 13/1. 2011. 69-84; Zapf \& Einarsen op. cit.

${ }^{26}$ SB Matthiesen \& S Einarsen. "MMPI-2: Configurations among victims of bullying at work". European Journal of Work and Organizational Psychology 10. 2001. 467-484.

${ }^{27}$ Owoyemi op. cit.

${ }^{28}$ Einarsen et al. op. cit.; Kalamdien, "The nature and prevalence ..." op. cit.; Miller \& Rayner op. cit.; Østvik \& Rudmin op. cit.; Owoyemi op. cit.; Vie et al. op. cit.; Zapf et al. op. cit.

${ }^{29}$ Einarsen et al. op. cit.; Vie et al. op. cit.

${ }^{30}$ DM Smit. "Bullying in the workplace: Towards a uniform approach in South African labour law". PhD thesis. University of the Free State, 2014.

${ }^{31}$ Kalamdien, The nature and prevalence ... op. cit.

${ }^{32} \mathrm{Du}$ Toit op. cit.; S Steinman. Workplace violence in the health sector: Country case study - South Africa. Geneva: ILO, 2003. 
${ }^{33}$ De Wet op. cit.; Jacobs \& De Wet op. cit.; Pietersen op. cit.

${ }^{34}$ Østvik \& Rudmin op. cit.

${ }^{35}$ Kalamdien, "The nature and prevalence ..." op. cit.

${ }^{36}$ PA Berry, GL Gillespie, D Gates \& J Schafer. "Novice nurse productivity

following workplace bullying”. Journal of Nursing Scholarship 44/1. 2012. 80-87.

${ }^{37}$ Steinmann op. cit.; Du Toit op. cit.

${ }^{38}$ De Wet \& Jacobs op. cit.

39 TA Bentley, B Catley, H Cooper-Thomas, D Gardner, MP O’Driscoll, A Dale \& L Trenberth. "Perceptions of workplace bullying in the New Zealand travel industry: Prevalence and management strategies". Tourism Management 33. 2012. 351-360.

${ }^{40}$ H Hoel, CL Cooper \& B Faragher. "The experience of bullying in Great Britain: The impact of organizational status". European Journal of Work and Organizational Psychology 10/4. 2001. 443-465.

${ }^{41}$ Berry et al. op. cit.

${ }^{42}$ Cunniff \& Mostert op. cit.

${ }^{43}$ Hoel et al. op. cit.

${ }^{44}$ L Glaso, E Bele, MB Nielsen \& S Einarsen. "Bus drivers' exposure to bullying at work: An occupational-specific approach". Scandinavian Journal of Psychology 52. 2011. 484-493.

${ }^{45}$ A Ortega, KB Christensen, A Hogh, R Rugulies \& V Borg. "One-year prospective study on the effect of workplace bullying on long-term sickness absence". Journal of Nursing Management 19. 2011. 752-759.

46 Ibid.

${ }^{47}$ D Keuskamp, AM Ziersch, FE Baum \& AD LaMontagne. "Workplace bullying a risk for permanent employees". Australian and New Zealand Journal of Public Health 36/2. 2012. 116-119.

${ }^{48}$ Kalamdien, "The nature and prevalence ..." op. cit.

${ }^{49}$ Hoel et al. op. cit.

${ }^{50} \mathrm{Du}$ Toit op. cit.; Glaso et al. op. cit.; Jacobs \& De Wet op. cit.; Owoyemi op. cit.; PR Peyton. Dignity at work: Eliminate bullying and create a positive working environment. New York: Brunner-Routledge, 2003; Vie et al. op. cit.

51 TL Vie, L Glaso \& S Einarsen. "How does it feel? Workplace bullying, emotions, and musculoskeletal complaints". Scandinavian Journal of Psychology 53. 2012. 165-173.

${ }^{52} \mathrm{C}$ Balducci, F Fraccaroly \& WB Schaufeli. "Workplace bullying and its relation with work characteristics, personality, and post-traumatic stress symptoms: 
An integrated model". Anxiety, Stress \& Coping 24/4. 2011. 499-513;

Jacobs \& De Wet op. cit.

${ }^{53}$ Einarsen \& Mikkelsen op. cit.; MAL Vartia. "Consequences of workplace

bullying with respect to the well-being of its targets and the observers of bullying”. Scandinavian Journal of Work Environment Health, 27/1. 2001. 63-69.

${ }^{54}$ Sims \& Sun op. cit.

${ }^{55}$ Bentley et al. op. cit.

${ }^{56}$ Owoyemi op. cit.

${ }^{57}$ Berry et al. op. cit.

58 Jacobs \& De Wet op. cit.

${ }^{59}$ Motsei op. cit.

${ }^{60}$ M Agervold \& E Mikkelsen. "Relationships between bullying, psychosocial work environment and individual stress reactions". Work \& Stress 18/4. 2004. 336-351; Owoyemi op. cit.; Vartia op. cit.

${ }^{61}$ R Kieseker \& T Marchant. "Workplace bullying in Australia: A review of current conceptualisations and existing research". Australian Journal of Management \& Organisational Behaviour 2/5. 1999. 61-75.

${ }^{62} \varnothing$ stvik \& Rudmin op. cit.

${ }^{63}$ Namie op. cit.

${ }^{64} \mathrm{~K}$ Egan. "Training and risk management for psychological injury". 2005.

<http://unionsafe.labor.net.au/safety_reps/files/Keryl_Egan_Clinical_Psycho logist.ppt> Accessed on 27 December 2016,

${ }^{65} \mathrm{~S}$ Einarsen. "The nature and causes of bullying at work". International Journal of Manpower 20/1\&/2. 1999. 16-27.

${ }^{66}$ Namie op. cit.

${ }^{67}$ Ibid.

${ }^{68}$ MG Harvey, JT Heames, RG Richey \& NL Leonard. "Bullying: From the playground to the boardroom". Journal of Leadership and Organizational Studies 12/4. 2006. 1-10.

${ }^{69}$ Archer op. cit.

${ }^{70}$ Harvey et al. op. cit.

${ }^{71}$ Ibid.; Egan op. cit.; Namie op. cit.

${ }^{72}$ RN Lussier. Management fundamentals: Concepts, applications, skill development. Mason, OH: Thomson Learning, 2003, 447.

73 Harvey et al. op. cit.

${ }^{74}$ Archer op. cit.; Owoyemi op. cit.

${ }^{75}$ Motsei op. cit. 
${ }^{76}$ RJ Waldinger. Psychiatry for medical students $\left(2^{\text {nd }}\right.$ ed.). Washington, DC: American Psychiatry Press, 1990.

77 JS Nevid, SA Rathus \& B Greene. Abnormal psychology: In a changing world ( $2^{\text {nd }}$ ed.). Englewood Cliffs, NJ: Prentice-Hall, 1994.

${ }^{78}$ Østvik \& Rudmin op. cit.; Owoyemi op. cit.

${ }^{79} \mathrm{G}$ Corey. Student manual for theory and practice of counselling and psychotherapy (9 ${ }^{\text {th }}$ ed.). Belmont, MA: Cengage Learning, 2012.

${ }^{80}$ Namie op. cit.

${ }^{81}$ Nevid et al. op. cit.

${ }^{82}$ Nevid et al. op. cit.; Waldinger op. cit.

83 P McCarthy, M Sheehan, S Wilkie \& W Wilkie. Bullying: Causes, costs and cures. Brisbane: Beyond Bullying Association, 1998; Motsei op. cit.

${ }^{84}$ Østvik \& Rudmin op. cit.

${ }^{85}$ Owoyemi op. cit.

${ }^{86}$ Ibid. 